\title{
Dynamic behaviour of an earthen material under different impact loading conditions
}

\author{
Luigi Fenu ${ }^{1}$, Francesco Aymerich ${ }^{2}$, Luca Francesconi ${ }^{2}$, Daniele Forni ${ }^{3}$, Nicoletta Tesio ${ }^{3}$, and Ezio Cadoni ${ }^{3, *}$ \\ ${ }^{1}$ Department of Civil Engineering, Environment Engineering and Architecture - University of Cagliari, Italy \\ ${ }^{2}$ Department of Mechanical, Chemical and Materials Engineering - University of Cagliari, Italy \\ ${ }^{3}$ DynaMat Laboratory, University of Applied Sciences of Southern Switzerland, Switzerland
}

\begin{abstract}
The dynamic behaviour of earthen materials reinforced with natural fibres is little studied although earth buildings are often built in seismic areas. In this paper the dynamic behaviour of an earthen material reinforced with hemp fibres under different impact loadings has been experimentally investigated. The dynamic response of the material in 3-point bending was investigated through an instrumented dropweight device, while the response in tension and in compression was investigated through a modified Hopkinson bar device. Typical impact response curves for tension, compression and bending impact tests have been obtained. The favourable effect of fibres in dissipating fracture energy under impact loads has been observed in all these types of test.
\end{abstract}

\section{Introduction}

Buildings in earthen materials still attract considerable interest. They are widespread in many developing countries and in rural areas, and are often of particular interest for architectural heritage [1-5]. About one third of the world's population still live in houses built of mud or unfired earth [6].

These types of buildings are technologically simple and highly energy-efficient. They have a very low carbon footprint, with low environment impact. Also, excellent sound and thermal insulation are provided [7, 8].

The low strength and the brittle behaviour are probably

the major issues for structural use of earth-based materials, particularly for buildings and constructions likely to be subjected to seismic events [9-13]. For this reason vegetal fibres (especially straw) are usually used to reinforce the earthen material [14]. In the literature there are many studies on improving the mechanical properties of the base material with straw, flax, sisal, jute and wool [15-19]

The addition of fibres plays a premier role in strengthening earthen construction materials [20-22], giving them not only higher tensile strength but also the ductility essential for their structural use. Then, the influence of fibres to improve the mechanical behaviour of earthen construction materials has shown to need specific investigations. In particular, fibres favourably affect also the impact behaviour of the earthen material [23-25]. In the literature there are some studies on the dynamic behaviour of adobe targets penetrated by projectiles [26-27].
This study examines the improvement in the dynamic behaviour provided by the addition of hemp fibres with different weight fractions in an earthen material.

The dynamic response of the materials was investigated by means of both tensile and bending impact tests. Static tests were also carried out, and the results compared with those of dynamic tests. Tensile impact tests were carried out on cylindrical specimens with diameter $20 \mathrm{~mm}$ and length $20 \mathrm{~mm}$ by using a modified Hopkinson bar device [28-38] Three-point bending impact tests on notched samples were carried out on prismatic samples by using an instrumented dropweight machine [23-24].

The main focus of the analyses was in the characterization of the structural properties of the materials in terms of fracture resistance, post-cracking performance and energy absorption capability at different strain rates.

The results of the study show that hemp fibres improve significantly the mechanical and fracture properties of the earthen material under both static and dynamic bending. It was also found that the structural properties of unreinforced and reinforced earthen materials are highly sensitive to the stress-rate, with higher strength and fracture resistance under impact loading than under static loading.

\section{Material characteristics}

The samples were prepared with soil from the quaternary sediments alongside the Tirso River near Oristano (Sardinia, Italy). This soil is traditionally used to manufacture earth bricks. Granulometry, obtained by

*Corresponding author: ezio.cadoni@supsi.ch 
sieving and hydrometer analyses in accordance with ASTM standard D422 [39] and Atterberg limits, show that the soil is an inorganic clay with low plasticity and low liquid limit (Unified Soil Classification System, USCS) [40]. X-ray diffraction revealed the presence of dominant quartz, together with illite and plagioclase.

The earthen samples were reinforced with hemp fibres $10 \mathrm{~mm}$ in length and with an average diameter of $0.2 \mathrm{~mm}$. Soil mixtures with two fibre weight fractions (2\% and $3 \%)$ were prepared.

\section{Sample preparation}

The mix to manufacture the samples was made of soil, hemp fibres and demineralized water.

Soil inclusions such as roots were manually removed before sieving the soil with a sieve mesh immediately higher than the maximum grain diameter of the soil. The soil was then crushed and dried $\left(40^{\circ} \mathrm{C}\right)$. The hemp fibres were manually chopped to $10 \mathrm{~mm}$ length. The water was then gradually added to the soil and the fibres until the desired water/soil weight ratio was attained.

The mix was then casted and manually compacted in perspex moulds $70 \times 70 \times 160 \mathrm{~mm}^{3}$ to obtain prismatic samples. All specimens were cured for 30 days $(48 \mathrm{~h}$ inside and 28 days out of the moulds) at room temperature and for 15 days in an oven at $40{ }^{\circ} \mathrm{C}$.

The central notch (depth $35 \mathrm{~mm}$ ) of notched samples was cut at sample mid-section using a diamond coated circular saw blade.

The cylindrical specimens were obtained through drilling the prismatic samples.

\section{Experimental testing}

Two types of dynamic tests were carried out in order to compare the dynamic response of the earthen material under two different types of impact load. Two different experimental set-ups were prepared.

\subsection{Experimental set-ups}

\subsubsection{Instrumented drop-weight impact testing machine}

The fracture behaviour and the dynamic response of the notched samples were investigated through a dropweight testing machine (Fig. 1), loading the samples in three-point-bending at medium strain rate. End support distance was $140 \mathrm{~mm}$, external force and support reaction were applied through steel cylinder $10 \mathrm{~mm}$ diameter.

Impact was provided through a $4.83 \mathrm{~kg}$ falling mass with an energy of about $50 \mathrm{~J}$, corresponding to approximately $1.05 \mathrm{~m}$ drop height and an impact velocity slightly higher than $4.5 \mathrm{~m} / \mathrm{s}$. A pneumatic braking system captured the falling mass after impact to avoid successive rebounds. Between the impactor top and the drop weigh was mounted a piezoelectric force transducer detecting the impact force.
The velocity of the impactor immediately before contact with the sample was measured with an infra-red sensor. Integration of the contact force signal as a function of time allowed to calculate impactor displacement and kinetic energy.

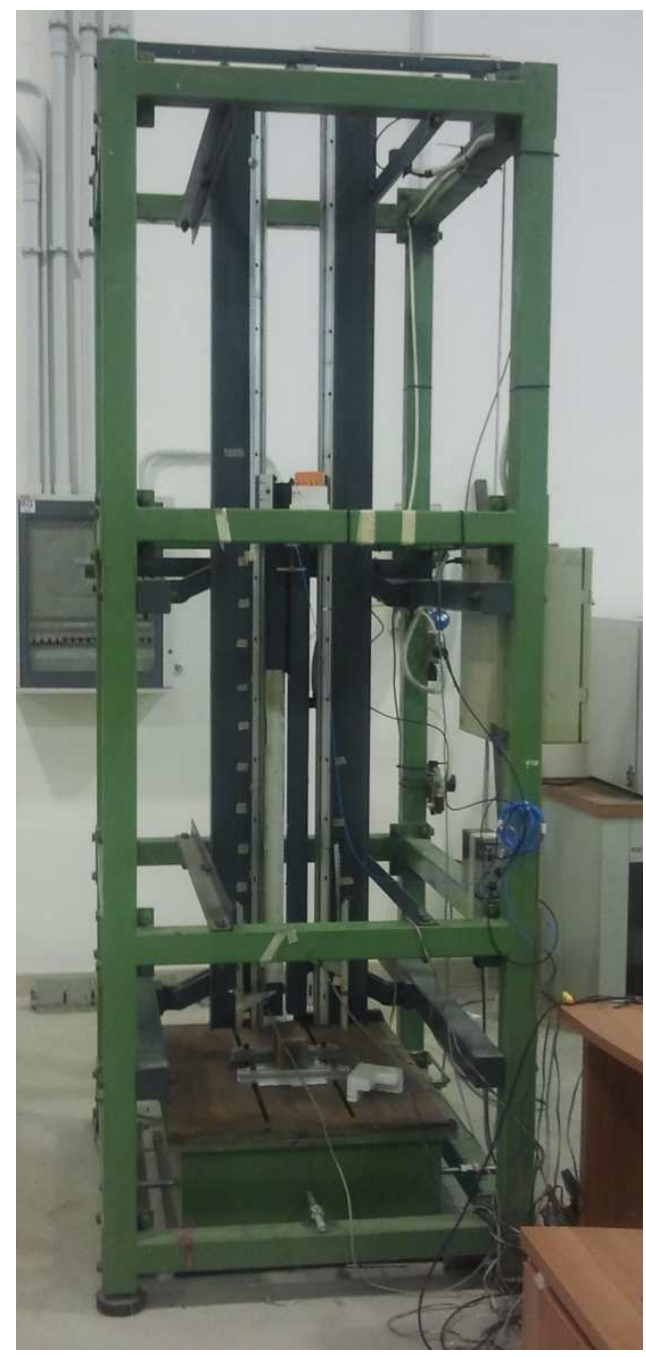

Fig. 1. Photo of the instrumented drop-weight machine.

\subsubsection{Modified Hopkinson Bar in tension and compression}

In order to analyse the dynamic behaviour of the fibrereinforced earthen materials two different experimental techniques are employed. The experimental set-ups and corresponding working principles for the high strain rate experiments are described in Figs. 2 and 3. The systems consist of a couple of aluminium bars (input and output bars) instrumented with strain gauges. The diameters of the bars differ for tension and compression test: $20 \mathrm{~mm}$ for the first and $30 \mathrm{~mm}$ for the second. The specimen is sandwiched between the input bar and the output bar. In case of tension test it is glued to the bars while in compression test is only in contact with a thin layer of grease. Both setups use a pre-tensioned bar to store elastic energy that is suddenly released to create a tensile or compression pulse in the input bar, which propagates to the specimen, where one part of the pulse reflects back in the input bar due to the impedance mismatch and 
the other part gets transmitted through the output bar. The brittle bolt is placed in different position in tension and compression tests as shown in Fig. 2. The details of the working principle are reported elsewhere [27-28, 32] and not repeated here for the sake of brevity.

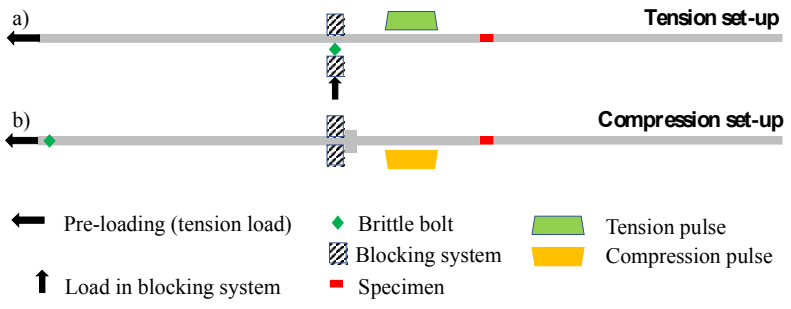

Fig. 2. Scheme of the Modified Hopkinson Bar in tension and compression.
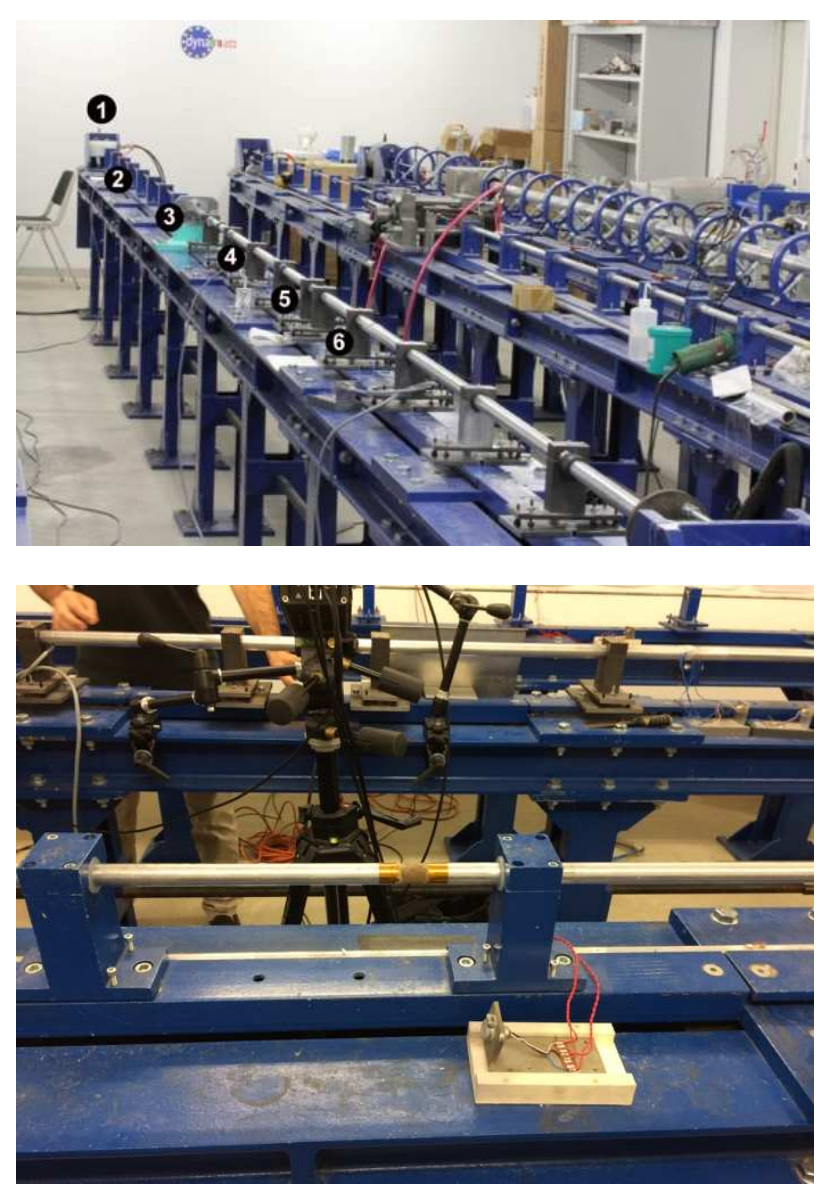

Fig. 3. Set-up in compression (up) and tension (down).

\section{Results}

Typical force-deflection curves of reinforced samples in three-point bending subjected to dynamic loads applied through the drop-weight bending test are shown in Fig. 4.

Because of the inertial effect in the sample, the force transducer on the impactor cannot measure the real bending load acting on the sample [41].

The real impact force for bending was hence calculated by subtracting the generalized inertial force from that measured by the force transducer on the impactor. The generalized inertial force was considered as a function of the acceleration at mid-span, with the acceleration along the sample assumed to vary linearly along it.

An accelerometer placed close to the notch on the lower side of the sample measured the sample acceleration history at mid-span during the impact event.
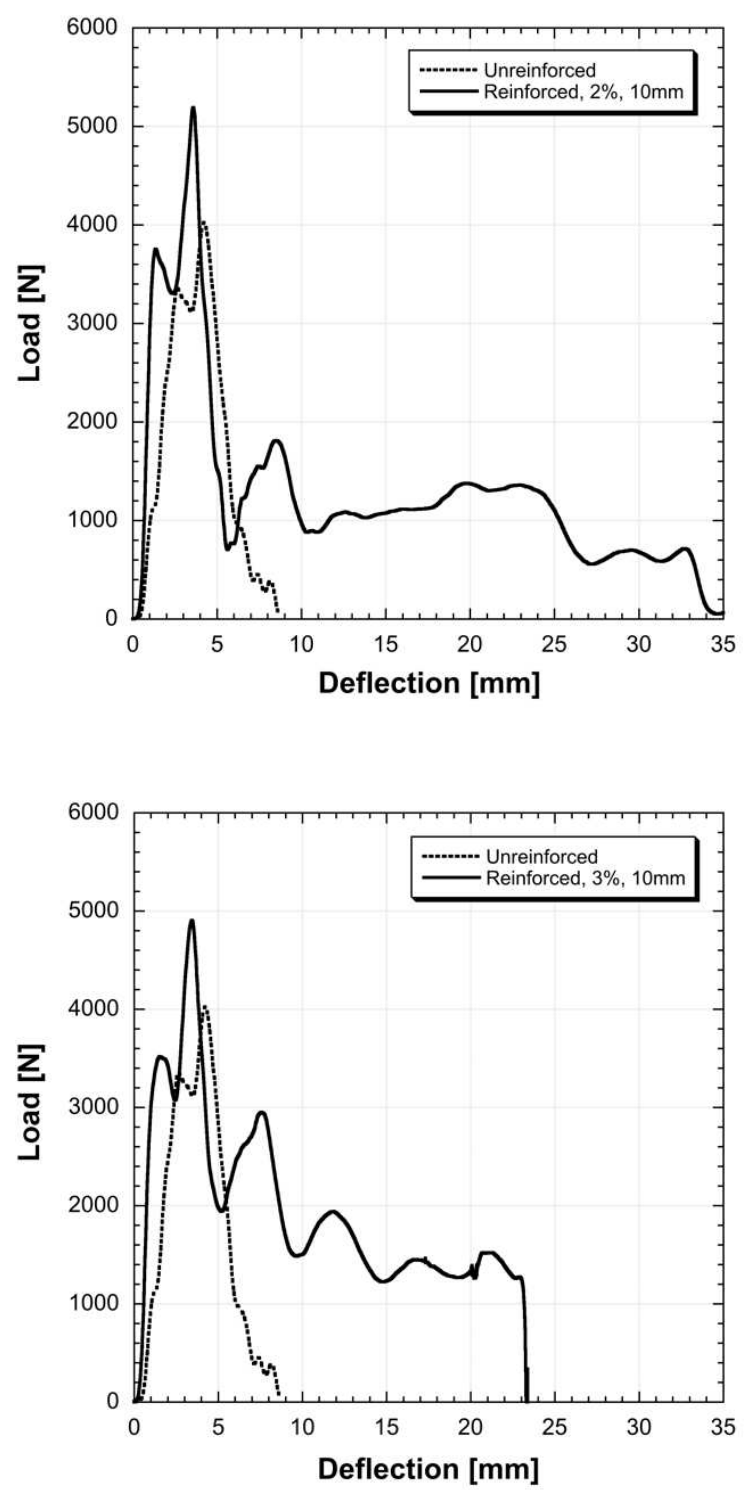

Fig. 4. Dynamic load versus deflections of 2 and $3 \%$ hemp fibre reinforced earthen material in bending.
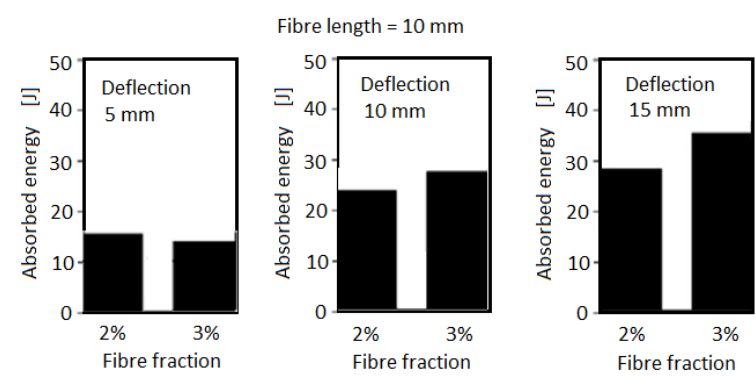

Fig. 5. Energy absorption of 2 and 3\% hemp fibre reinforced adobe material in bending for increasing deflection values. 
Fig. 4 shows the impact response of the unreinforced materials, with an abrupt drop of the applied load at a deflection of about $4 \mathrm{~mm}$. The subsequent post-peak behaviour shows that the load sustained by the sample quickly decreases to zero, because of the brittle collapse due to the unstable propagation of a macro-crack from the notch tip.

Conversely, samples reinforced with hemp fibres (length $10 \mathrm{~mm}$, fibre content of 2 and 3\%) exhibit, under impact loading, peak loads similar to the unreinforced samples, but higher residual strengths at large deflections, as well as higher fracture energy, irrespectively of fibre content.

Fig. 5 shows that while for low deflection values $(5 \mathrm{~mm})$ energy absorption of samples with fibre content 2 and $3 \%$ was similar, for higher deflection values samples with 3\% fibre content samples with 3\% fibre content dissipate higher energy than samples with $2 \%$ fibre content.

Table 1. Results of the dynamic tension tests.

\begin{tabular}{|c|c|c|c|c|c|}
\hline Material & $\begin{array}{c}\text { Stress- } \\
\text { rate } \\
{[\mathbf{G P a} / \mathbf{s}]}\end{array}$ & $\begin{array}{c}\text { Max. } \\
\text { stress } \\
{[\mathbf{M P a}]}\end{array}$ & $\begin{array}{c}\text { Fract. } \\
\text { strain } \\
{[\%]}\end{array}$ & $\begin{array}{c}\text { Fract. } \\
\text { time } \\
{[\boldsymbol{\mu} \mathbf{s}]}\end{array}$ & $\begin{array}{c}\text { Tot. } \\
\text { energy } \\
{\left[\mathbf{J} / \mathbf{m}^{2}\right]}\end{array}$ \\
\hline $2 \%$ & 48 & 2.6 & 0.19 & 63 & 1790 \\
\hline $3 \%$ & 50 & 2.6 & 0.22 & 66 & 5198 \\
\hline
\end{tabular}

Table 2. Results of the dynamic compression tests.

\begin{tabular}{|c|c|c|c|c|c|}
\hline Material & $\begin{array}{c}\text { Stress- } \\
\text { rate } \\
{[\mathbf{G P a} / \mathbf{s}]}\end{array}$ & $\begin{array}{c}\text { Max. } \\
\text { stress } \\
{[\mathbf{M P a}]}\end{array}$ & $\begin{array}{c}\text { Fract. } \\
\text { strain } \\
{[\%]}\end{array}$ & $\begin{array}{c}\text { Fract. } \\
\text { time } \\
{[\boldsymbol{\mu} \mathbf{s}]}\end{array}$ & $\begin{array}{c}\text { Tot. } \\
\text { energy } \\
{\left[\mathbf{J} / \mathbf{m}^{2}\right]}\end{array}$ \\
\hline $2 \%$ & 29 & 8.6 & 2.77 & 360 & 10129 \\
\hline $3 \%$ & 22 & 6.8 & 3.74 & 393 & 12476 \\
\hline
\end{tabular}

In general, the pull-out process of the fibres governs the post failure region. The small diameter of the fibres as well as their percentage influence positively the phenomena with a high dissipation of energy.

The results of the dynamic tests in tension and compression carried out through using the modified Hopkinson bar device are reported in Table 1 and Table 2 , respectively.

The stress versus time curves of the $2 \%$ and $3 \%$ fibrereinforced earthen samples tested in tension and in compression are plotted, respectively, in Figures 6 and 7 and in Figures 8 and 9. It can be observed how, similarly to the samples tested in 3-point bending, the increase of hemp fibre content increases the energy dissipation, thus improving the composite post-peak behaviour.

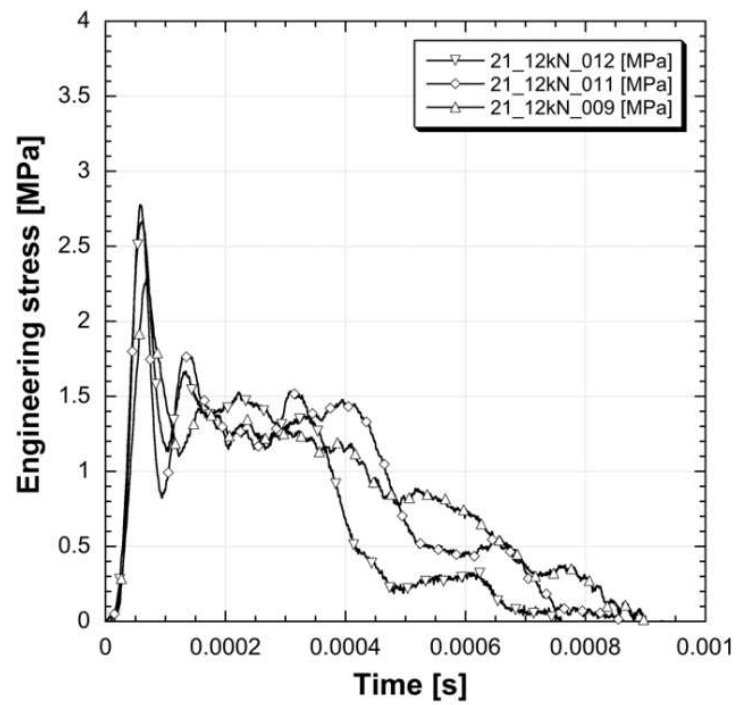

Fig. 6. Dynamic stress versus time curves of $2 \%$ hemp fibre reinforced adobe material in tension.

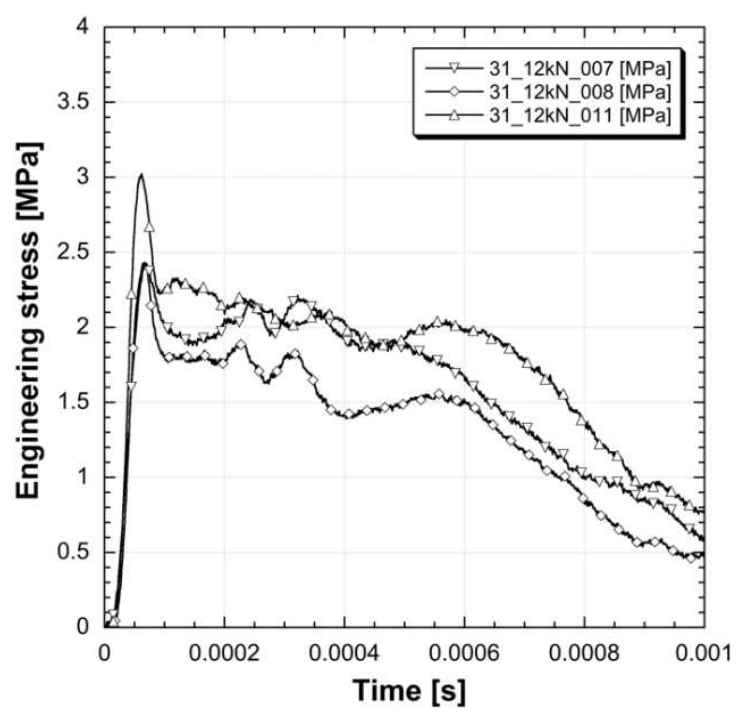

Fig. 7. Dynamic stress versus time curves of $3 \%$ hemp fibre reinforced adobe material in tension.

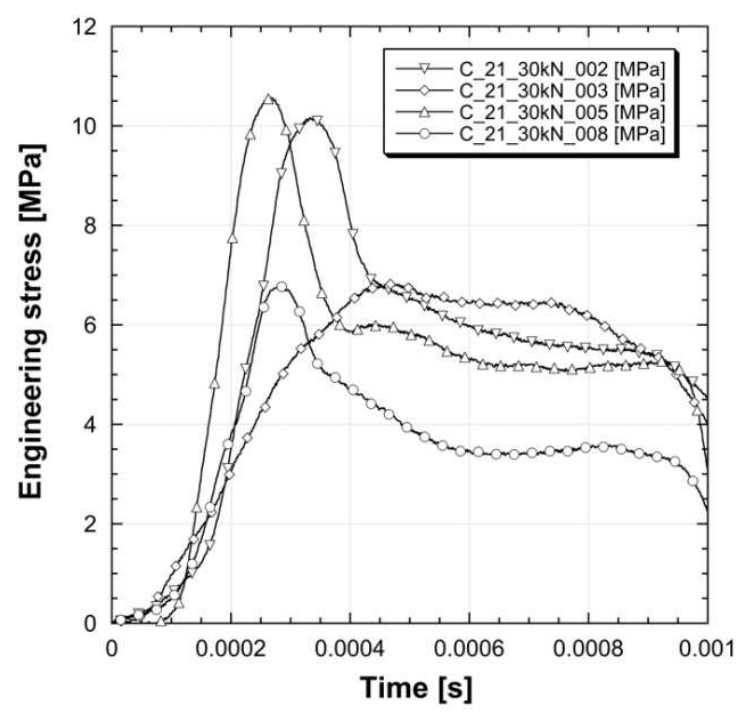

Fig. 8. Dynamic stress versus time curves of $2 \%$ hemp fibre reinforced adobe material in compression. 


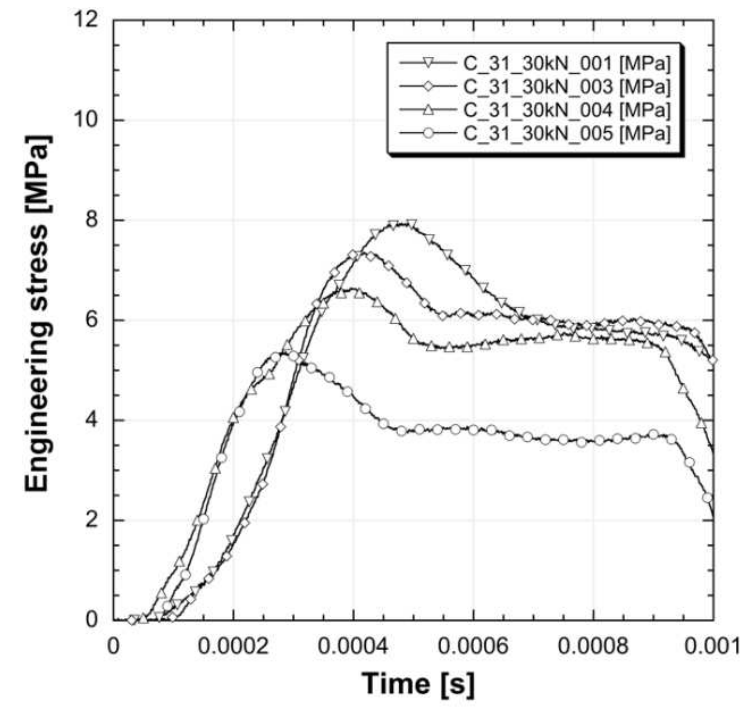

Fig. 9. Dynamic stress versus time curves of $3 \%$ hemp fibre reinforced adobe material in compression.

The samples tested in tension show to have same abrupt drop of the applied load immediately after the peak load as the samples subjected to bending. In both cases, this sudden strength decrease after peak load is reduced by the increase in fibre content from 2 to $3 \%$ (compare the plots in Figure 4, and Fig. 6 with Fig.7).

In the samples tested in compression the drop of the applied load was shown to be smoother than in the previous cases, because, contrary to the samples tested in tension, the fibre pull-out mainly occurred in the diameter directions orthogonally to the direction of the applied load.

It can be noted that the samples tested in compression appear to be less rigid than the samples tested in tension. This is reasonably due to the fact that while the fibres work well in tension in reinforcing the earthen material, they are not effective in reinforcing the samples loaded in compression. In this case, in the compression direction they have the effect of flaws that weaken the material, while the only favourable effect is to dissipate energy with the fibre pull-out in the diameter direction.

\section{Conclusions}

Reinforcing the earthen material with fibres is a traditional practice in earth construction because highly reduces brittleness of the earthen material and increases earth buildings ductility. This effect is of particular importance in seismic areas, where earth constructions are frequently built.

In this study the effect of reinforcing the earthen materials with fibres when dynamic loads are applied has been experimentally investigated.

The earthen material reinforced with hemp fibres subjected to impact loads has been investigated in bending (carrying out drop-weight bending tests), as well as in tension and in compression using a modified Hopkinson bar device.

Typical impact response curves for these three types of tests have been obtained. The favourable effect of fibres in dissipating energy in all these dynamic tests has been observed. This is a favourable property for buildings in seismic areas.

Research funding was provided by the Sardinian Regional Government (LR N.7 7-8-2007, Tender 3, 2011).

\section{References}

1. H. Houben, H. Guillaud, CRATerre-EAG Earth Construction: A Comprehensive Guide. Intermediate Technology Publications (1994)

2. G. Minke Earth construction handbook: the building material earth in modern architecture. Wit Press (2000)

3. G. Minke Building with Earth: Design and Technology of a Sustainable Architecture. Birkhäuser (2006)

4. H. Varum, N. Tarque, D. Silveira, et al. Structural Behaviour and Retrofitting of Adobe Masonry Buildings. In: Costa, Guedes, Varum (eds) Structural Rehabilitation of Old Buildings. Springer Berlin Heidelberg, New York, pp 37-75 (2014)

5. A. Costa, JM. Guedes, H. Varum Structural Rehabilitation of Old Buildings. New York (2014)

6. EC. Avrami, H. Guillaud, M. Hardy, GC Institute Terra Literature Review: An Overview of Research in Earthen Architecture Conservation. Getty Conservation Institute (2008)

7. H. Binici, O. Aksogan, MN. Bodur, et al., Constr Build Mater 21 901-906 (2007)

8. M. Bouhicha, F. Aouissi, S. Kenai. Cem Concr Compos 27 617-621 (2005)

9. D. Asprone, F. Parisi, A. Prota, et al., Adobe in Sardinia. Static and dynamic behaviour of the earthen material and of adobe constructions. In: 16th Inter. Brick \& Block Masonry Conference. Padova (2016)

10. A. Figueiredo, H. Varum, A. Costa, et al., Mater Struct 46 203-219 (2013)

11. M Blondet, J. V, Tarque N. Observed behaviour of earthen structures during the Pisco (Peru) earthquake of August 15, 2007. In: Proc. 14th World Conference on Earthquake Engineering. Beijing (2008)

12. P. Gavrilovic, V. Sendova, et al. Shaking Table Tests of Adobe Structures. Skopje (1996)

13. MS. Islam, K. Iwashita, Seismic Response of FiberReinforced and Stabilized Adobe Structures. In: Proceedings of the Getty Seismic Adobe Project 2006 Colloquium (2006)

14. G. Calatan, A Hegyi, C Dico, C Mircea, Procedia Technol 22 259-265 (2016)

15. M. Achenza, L. Fenu, Mater Struct 39 21-27 (2007)

16. F. Aymerich, L. Fenu, P. Meloni, Constr Build Mater 27 66-72 (2012).

17. K. Ghavami, RD. Toledo Filho, NP. Barbosa, Cem Concr Compos 21 39-48 (1999)

18. F. Clementi, S. Lenci, T. Sadowski, Int J Fract 149 193-198 (2008)

19. C. Galán-Marín, C. Rivera-Gómez, J. Petric, Constr 
Build Mater 24 1462-1468 (2010)

20. F. Parisi, D. Asprone, L. Fenu, A. Prota, Compos Struct 122 300-307 (2015)

21. Q. Piattoni, E. Quagliarini, S. Lenci, Constr Build Mater 25 2067-2075 (2011)

22. H. Binici, O. Aksogan, T. Shah, Constr Build Mater 19 313-318 (2005)

23. F. Aymerich, L. Fenu, L. Francesconi, P. Meloni, EPJ Web Conf 941043 (2015)

24. F. Aymerich, L. Fenu, L. Francesconi, P. Meloni, Constr Build Mater 109 109-119 (2016)

25. F. Matta, M. Cuéllar-Azcárate, E. Garbin, Earthen Masonry Dwelling Structures for Extreme Wind Loads (2015)

26. C. Sauer C, A Heine, KE. Weber, W. Riedel, Int J Impact Eng 109 67-77 (2017)

27. A Heine, M Wickert, Int J Impact Eng 75 27-29 (2015)

28. L. Kruszka, W. Moćko, L. Fenu, E. Cadoni, EPJ Web Conf 945008 (2015)

29. E. Cadoni, L. Fenu, D. Forni, Constr Build Mater 35 399-407 (2012)

30. L. Fenu, D. Forni, E. Cadoni, EPJ Web Conf 94 1030 (2015)

31. L. Fenu, D. Forni, E. Cadoni, Comp. Part B: Engg 92(5) 142 - 150 (2016)

32. E. Cadoni, D. Forni, EPJ-ST 225(2), 253-264 (2016)

33. L. Coppola, E. Cadoni, D. Forni, A. Buoso, Appl. Mech. Mat. 82, 190-195 (2011)

34. D. Asprone, E. Cadoni, A. Prota , G. Manfredi, ASCE J. Comp. Constr. 13(6), 558-564 (2009)

35. E. Cadoni, C. Albertini, G. Solomos, J. de Phys. IV 134, 647-652 (2006)

36. E. Cadoni, G. Solomos, C. Albertini, Mag. Concr. Res. 61(3), 221-230 (2009)

37. E. Cadoni, G. Solomos, C. Albertini, Mag. Conc. Res. 65(11), 660-672 (2013)

38. D. Asprone, E. Cadoni, F. Iucolano, A. Prota, Cem. Conc. Comp. 53(10), 52-58. (2014)

39. (2007) ASTM Standard D422-63, Standard test method for particle-size analysis of soils. ASTM International

40. (2011) ASTM Standard D2487-11, Standard practice for classification of soils for engineering purposes (Unified Soil Classification System).ASTM International

41. N. Banthia, S. Mindess, A. Bentur, M. Pigeon, Exp Mech 29 63-69 (1989) 